\title{
ANALISIS PENGENDALIAN MUTU FRUTIVEZ PADA PT. SABUSI DENGAN PENDEKATAN STATISTICAL PROCESS CONTROL (SPC)
}

\section{QUALITY CONTROL ANALYSIS OF FRUTIVEZ AT PT. SABUSI WITH STATISTICAL PROCESS CONTROL (SPC)}

\author{
Sasvia Ayu Puzianti*, Totok Pujianto, Roni Kastaman \\ Program Studi Teknologi Industri Pertanian, Universitas Padjadjaran \\ Jl. Raya Bandung-Sumedang Km. 21, Jatinangor, Jawa Barat 45363 \\ *E-mail: sasvia17001@mail.unpad.ac.id \\ (Diterima 14-09-2021; Disetujui 15-12-2021)
}

\begin{abstract}
ABSTRAK
Pengendalian mutu merupakan hal dasar yang perlu diterapkan oleh sebuah organisasi, instansi, maupun perusahaan untuk mengahasilkan jasa ataupun produk yang dapat memenuhi kebutuhan konsumen. Kecacatan yang mungkin terjadi dalam suatu produksi dapat menyebabkan kerugian secara bertahap bagi perusahaan. Fruit strips Frutivez secara keseluruhan dapat memenuhi standar fruit strips yang diminati oleh konsumen, namun sering produk yang diterima oleh konsumen dalam keadaan patah. Kecacatan disebabkan oleh karena faktor tenaga kerja (karyawan dan kurir), kejenuhan karyawan, dan peralatan yang sudah usang. Solusi yang diberikan adalah perbaikan metode pengemasan, mengadakan rekreasi bersama, serta penggantian dan pemeliharaan peralatan. Tingkat presentase akhir penerimaan solusi tersebut oleh pihak perusahaan sebesar $78 \%$ yang berarti kemungkinan besar solusi yang diberikan dapat diimplementasikan.
\end{abstract}

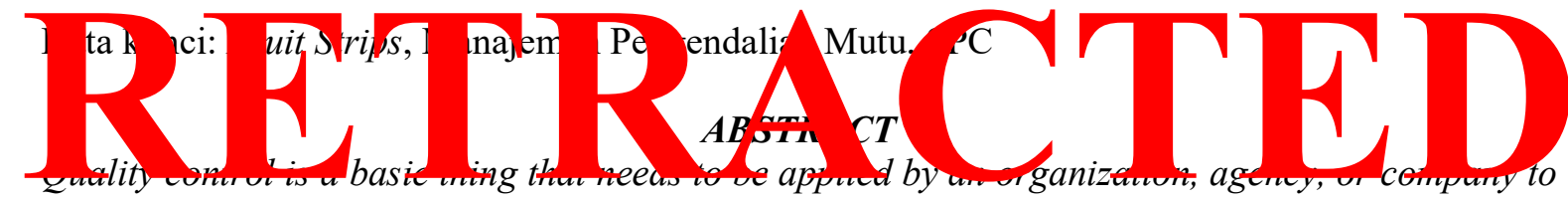
produce services or products that can meet consumer needs. Defects that may occur in a production can cause gradual losses for the company. Fruit strips Frutivez as a whole meet the standards of fruit strips that consumers want, but often the products received by consumers are damaged. Disability is caused by labor factors (employees and couriers), employee boredom, and equipment that is no longer suitable for use. The solutions provided are improving packaging methods, holding joint recreation, and equipment replacement and maintenance. The final percentage rate of acceptance of the solution by the company is $78 \%$, which means it is very likely that the given solution can be implemented.

Keywords: Fruit Strips, Quality Control Management, SPC

\section{PENDAHULUAN}

Kesehatan merupakan hal yang sangat penting dalam kehidupan manusia karena apabila kesehatan terganggu maka aktivitas pun menjadi terhambat. Pentingnya menjaga kesehatan mendorong kecenderungan masyarakat untuk mengonsumsi makanan yang bernutrisi dan bervitamin untuk menjaga imunitas tubuh. Konsumsi sayur dan buah merupakan hal yang paling umum dilakukan untuk pemenuhan vitamin dan serat bagi tubuh. Manfaat baik dari sayur dan buah ini seringkali berbanding 
terbalik dengan minat konsumsi sayur dan buah terutama pada anak-anak. Anak-anak cenderung lebih menyukai camilan seperti keripik, permen, cokelat, dan sebagainya.

Tubuh hanya memerlukan kadar vitamin yang relatif kecil namun, kebutuhan akan vitamin sangat penting untuk menjaga stamina tubuh. Vitamin diperoleh oleh tubuh dengan mengonsumsi sayur dan buah karena tubuh tidak dapat memproduksi vitamin yang cukup untuk kebutuhan vitamin harian. Konsumsi sayur dan buah sangat penting untuk menjaga kesehatan tubuh (Hamidah, 2015).

Fruit strips atau yang lebih umum dikenal sebagai fruit leather merupakan produk makanan olahan yang terbuat dari bubur daging buah (pure) yang berbentuk lembaran tipis 2-3 $\mathrm{mm}$ dan dikeringkan hingga kadar airnya mencapai $10-15 \%$. Rasa yang dihasilkan setiap fruit strips berbeda-beda tergantung dari jenis buah yang digunakan. Rasa manis saat mengonsumsi fruit strips berasal dari pemanis alami yang terkandung dalam buah dan bukan berasal dari adanya penambahan gula. Buah-buahan yang dapat dijadikan sebagai bahan baku fruit strips antara lain adalah mangga, pisang, nenas, papaya, apel, nangka, jambu biji, sirsak, bunga rosella, peach, dan sebagainya (Enie \& Nami, 1992).

Setiap konsumen memiliki kebutuhan dan juga keinginan yang beraneka ragam. Perusahaan berusaha untuk memenuhi seluruh keberagaman dari keinginan konsumen tersebut. Jumlah ragam varian dari produk yang dihasilkan tidak terlalu dipermasalahkan oleh konsumen apabila mutu dari produk yang dihasilkan oleh perusahaan dapat mencapai permintaan konsumen. Pengendalian mutu diperlukan selain untuk menjawab kepuasan konsumen yaitu agar perusahaan tetap mampu bersaing di zaman ini (Elan \& Kusmindah, 2016). Konsumen akan merasa puas terhadap barang atau jasa suatu perusahaan apabila mutu produk yang diberikan sesuai standar. Pengendalian mutu termasuk ke dalam hal yang wajib dilakukan oleh suatu perusahaan agar dapat mengurangi resiko adanya produk cacat (Amanah, 2010).

Tambahan biaya untuk melakukan pengawasan mutu ini berdampak pada pengeluaran biaya perusahaan tetapi, manfaat yang didapatkan apabila perusahaan melakukan sebuah pengendalian mutu pun sebanding dengan biaya yang harus dikeluarkan di awal. Perusahaan yang melakukan 
pengendalian mutu ini akan lebih mudah untuk memasarkan produknya karena mutu produk yang dihasilkan baik dan tidak banyak dihasilkannya produk yang cacat (Elmas, 2017). Manajemen pengendalian mutu merupakan hal yang perlu diterapkan oleh seluruh unit dalam suatu sistem organisasi ataupun perusahaan yang bertujuan untuk memberikan layanan (jasa) atau produk yang dapat memuaskan konsumen (Winarsih, 2017).

Tujuan dari pengendalian mutu itu sendiri adalah untuk meyakinkan konsumen bahwa produk yang dihasilkan oleh perusahaan memiliki mutu yang baik dan mampu menjawab kebutuhan konsumen (Ramadhany \& Supriono, 2015). Angka cacat yang menurun dapat mengurangi biaya perbaikan sehingga laba yang dihasilkan oleh perusahaan pun akan semakin tinggi (Mardiyani, 2018). Kepercayaan konsumen terhadap suatu perusahaan dapat dilihat dari baik atau tidaknya kualitas atau mutu dari produk yang dihasilkan, sehingga pengendalian mutu ini sangat diperlukan untuk menjaga nama baik perusahaan (Nastiti, 2014).

PT. Saudagar Buah Indonesia (PT. SABUSI) merupakan perusahaan yang bergerak dalam bidang pengembangan produk turunan pangan dan memproduksi fruit strips. Produk fruit strips yang diproduksi oleh perusahaan ini mempunyai merek dagang Frutivez. Fruit strips yang diolah oleh Frutivez memiliki 3 varian yang terbuat dari olahan pure mangga, pinepaya yang merupakan campuran pepaya dan nanas, serta pisang. Proses produksi yang dilakukan oleh perusahaan umumnya masih dilakukan secara manual mulai dari pemotongan buah, penghalusan buah menggunakan blender, perataan pure pada tray (loyang), hingga proses pemotongan dan juga pengemasan.

Pengendalian mutu yang diterapkan oleh perusahaan dalam proses produksi pun masih terbatas dan belum ada penerapan metode pengendalian mutu di dalamnya. Maka dari itu, perusahaan perlu menerapkan pengendalian mutu dalam proses produksinya. Salah satu metode yang dapat diterapkan untuk pengendalian mutu adalah metode Statistical Process Control (SPC).

Statistical Process Control (SPC) merupakan alat yang dapat digunakan untuk mengendalikan kinerja proses menggunakan metode statistik, Analisis pengendalian mutu kemudian dapat dilanjutkan dengan menganalisis faktor pengaruh pengendalian mutu, penyebab 


\section{ANALISIS PENGENDALIAN MUTU FRUTIVEZ PADA PT. SABUSI \\ DENGAN PENDEKATAN STATISTICAL PROCESS CONTROL \\ Sasvia Ayu Puzianti, Totok Pujianto, Roni Kastaman}

masalah, serta mengidentifikasi kesesuaian mutu dengan standar yang ada (Nissa, 2018; Tarmoem, 2018). Terdapat instrumen yang biasanya digunakan dalam mengukur pengendalian mutu dengan metode SPC yang merupakan bagian dari seven tools. Alat-alat tersebut antara lain adalah peta kendali (control chart), histogram, diagram pareto (pareto analysis), dan juga diagram sebab-akibat (cause an effect diagram atau fishbone) (Heizer \& Render, 2011).

Merujuk pada uraian sebelumnya, belum adanya penerapan metode pengendalian mutu terhadap produk Frutivez yang dihasilkan oleh PT. Saudagar Buah Indonesia, sehingga penelitian bertujuan untuk menganalisis mengenai pendekatan penerapan metode pengendalian mutu untuk produk Frutivez menggunakan metode statistical process control (SPC) yang berfokus pada pengendalian mutu produk. Penentuan standar fruit strips yang diminati oleh konsumen ini dilihat dari segi rasa, warna, ukuran, ketebalan, tekstur permukaan, dan juga bentuk. Berdasarkan kuesioner pendahuluan yang sudah disebarkan kepada 100 responden, didapatkan data bahwa konsumen memperhatikan produk fruit strips dari segi rasa, ukuran, ketebalan, tekstur permukaan, dan juga bentuk sehingga penelitian ini akan berfokus kepada variabel-variabel tersebut.

\section{METODE PENELITIAN}

Penelitian ini dilakukan di PT. Saudagar Buah Indonesia (Sabusi) yang berlokasi di Jl. Gkpn Perumahan Grand Cipacing No.42, Jatinangor, Jawa Barat. Penelitian ini berlangsung pada bulan Mei hingga Agustus 2021. Fokus penelitian ini akan berfokus pada kesesuaian mutu produk fruit strips dengan mutu produk sesuai dengan yang diharapkan konsumen. Atribut yang dinilai tersebut adalah rasa, tekstur permukaan, dan bentuk produk, sementara variabel yang dapat diukur adalah ukuran dan juga ketebalan produk yang diambil datanya menggunakan teknik random sampling. Rumus yang digunakan untuk control chart dalam penelitian ini sebagai berikut (Montgomery, 2009; Oakland, 2008; Stapenhurst, 2005):

- X-bar - R-Chart

$$
\dot{\mathrm{X}}=\left(\sum \mathrm{Xi}\right) / \mathrm{n}
$$

Keterangan:

$\dot{\mathrm{X}}=\mathrm{X}$ bar

$\mathrm{Xi}=$ jumlah produk yang tidak sesuai dalam populasi $\mathrm{n}=$ jumlah populasi 
$\mathrm{XDbl}$ bar $=\left(\sum \mathrm{Xi}\right) / \mathrm{n}$

Keterangan:

$\mathrm{Xi}=$ jumlah produk yang tidak sesuai dalam populasi

$\mathrm{n}=$ jumlah populasi

$$
\mathrm{R}=\mathrm{Xi} \text { maks }-\mathrm{Xi} \min
$$

\section{Keterangan:}

$\mathrm{Xi}$ maks $=$ Nilai $\mathrm{X}$ maksimal dalam 1 hari

$\mathrm{Xi} \min =$ Nilai $\mathrm{X}$ minimal dalam 1 hari

$$
\hat{\mathrm{R}}=\left(\sum \mathrm{R}\right) / \mathrm{N}
$$

Keterangan:

$\hat{\mathrm{R}}=\mathrm{R}$ bar

$\Sigma \mathrm{R}=$ Total nilai range

$\mathrm{N}=$ Populasi

$$
\begin{aligned}
& \text { CL X-bar }=\ddot{X}=\left(\sum \dot{X}\right) / N \\
& \text { CL R-Chart }=\hat{\mathrm{R}} \\
& \text { UCL X-bar }=\ddot{\mathrm{X}}+(\mathrm{A} 2 * \hat{\mathrm{R}}) \\
& \text { UCL R-Chart }=\mathrm{D} 4 * \hat{\mathrm{R}} \\
& \text { LCL X-bar }=\ddot{\mathrm{X}}-(\mathrm{A} 2 * \hat{\mathrm{R}}) \\
& \text { LCL R-Chart }=\mathrm{D} 3 * \hat{\mathrm{R}}
\end{aligned}
$$

Keterangan:

Nilai konstanta A2, D2, D3, dan D4 merupakan nilai yang diambil dari Tabel konstanta untuk control chart.

- p-Chart

$$
\mathrm{P}=\mathrm{np} / \mathrm{n}
$$

\section{Keterangan:}

$\mathrm{P}=$ nilai rata-rata produk tidak sesuai $\mathrm{np}=$ jumlah produk yang tidak sesuai $\mathrm{n}=$ jumlah sampel

$$
\begin{aligned}
& \mathrm{UCL}=\mathrm{P}+3 \sqrt{ }((\mathrm{P}(1-\mathrm{P})) / \mathrm{n}) \\
& \mathrm{LCL}=\mathrm{P}-3 \sqrt{ }((\mathrm{P}(1-\mathrm{P})) / \mathrm{n}) \\
& \mathrm{CL}=\mathrm{P}
\end{aligned}
$$

\section{Keterangan:}

UCL = Nilai batas kendali atas

LCL = Nilai batas kendali bawah

$\mathrm{P}=$ nilai rata-rata produk tidak sesuai

Pengukuran sampel dalam penelitian ini bersifat dapat merusak produk sehingga jumlah sampel yang digunakan hanya sedikit dan termasuk ke dalam destructive measurement (Mast \& Trip, 2005). Peta kendali yang digunakan untuk perhitungan variabel penelitian (variabel ukuran dan ketebalan) adalah jenis x-bar - R-Chart, sementara untuk penilaian atribut penelitian (atribut rasa, bentuk, dan tekstur permukaan) adalah jenis p-Chart. Pengukuran variabel dilakukan oleh peneliti, sementara untuk penilaian atribut dinilai oleh dua orang tenaga ahli serta peneliti. Hasil pengukuran yang didapatkan kemudian dikonfirmasi dengan standar produk yang diharapkan oleh konsumen berdasarkan data yang diperoleh melalui penyebaran kuesioner. Jika nilai perhitungan melebihi garis kendali bawah (LCL) maka sampel tersebut dinyatakan sesuai standar, sedangkan jika nilai perhitungan melebihi garis kendali atas (UCL) maka sampel 
dinyatakan tidak sesuai dengan standar.

Sampel yang dinyatakan dalam batas standar adalah sampel dengan hasil perhitungan yang berada diantara garis kendali bawah dan garis kendali atas.

Ketidaksesuaian sampel dengan standar diidentifikasi faktor penyebabnya melalui wawancara dengan stakeholder yang bersinggungan langsung dengan proses produksi. Hasil wawancara ini dianalisis lebih lanjut faktor penyebab kecacatan tersebut menggunakan diagram sebab-akibat (fishbone diagram). Perbaikan diperlukan guna mengurangi jumlah produk cacat yang mungkin dihasilkan dalam produksi fruit strips Frutivez.

\section{HASIL DAN PEMBAHASAN}

Frutivez merupakan merek dagang untuk produk fruit strips yang diproduksi oleh PT. Saudagar Buah Indonesia (PT. Sabusi) sejak tahun 2019. Hingga tahun 2021, terdapat tiga varian rasa Frutivez yaitu varian mangga, pisang, dan pinepaya yang merupakan campuran dari buah pepaya dan nenas. Penjualan Frutivez dilakukan secara online yang dapat dijumpai pada e-commerce seperti Shopee, Tokopedia, dan Blibli, serta secara offline yang dapat dibeli pada beberapa toko mitra di daerah Bandung dan Jabodetabek.

Berdasarkan pengamatan terhadap sampel yang dilakukan selama 30 hari produksi, didapatkan hasil bahwa fruit strips Frutivez secara keseluruhan mendekati standar minat konsumen, namun terdapat data penyimpangan pada bentuk produk. Penyimpangan bentuk produk ini terjadi pada hari ke-4 untuk varian mangga dan pinepaya dengan tanggal produksi 19 Juli 2021 yang bertepatan satu hari sebelum hari raya Idul Adha serta pada hari ke-14 untuk varian pisang dengan tanggal produksi 29 Juli 2021 dimana salah seorang karyawan divisi produksi izin tidak masuk kerja. Penyimpangan ini adalah penyimpangan yang melewati batas kendali atas (UCL) dimana untuk bentuk varian mangga adalah 0,87 sementara datanya adalah 0,93 , untuk bentuk varian pinepaya UCLnya adalah 0,84 sementara datanya adalah 0,87 , dan bentuk varian pisang memiliki UCL sebesar 0,92 sedangkan datanya sebesar 0,93 .

Data untuk variabel dan atribut selain bentuk mengalami naik (run up) dan turun (run down) yang juga tidak beraturan, namun data-data tersebut masih berada dalam batas garis kendali atas dan bawah. Perbedaan jarak yang 
besar antara garis kendali atas dan garis kendali bawah ini sebaiknya diminimalisir untuk menandakan bahwa produk yang dihasilkan seragam. Berikut disajikan grafik data sampel fruit strips Frutivez untuk atribut rasa, bentuk, dan tekstur permukaan dalam Gambar 1. Serta untuk variabel ukuran dan ketebalan dalam Gambar 2.



(a)

p-chart Rasa Pinepaya

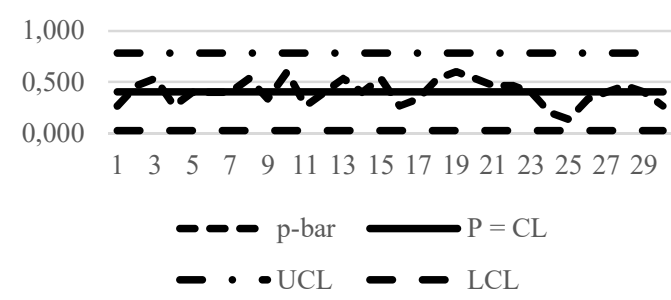

(b)

p-chart Rasa Pisang

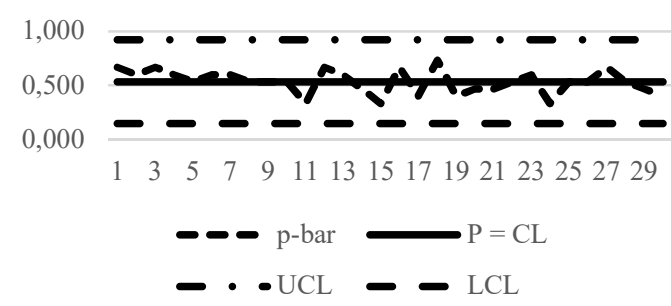

p-chart Bentuk Mangga

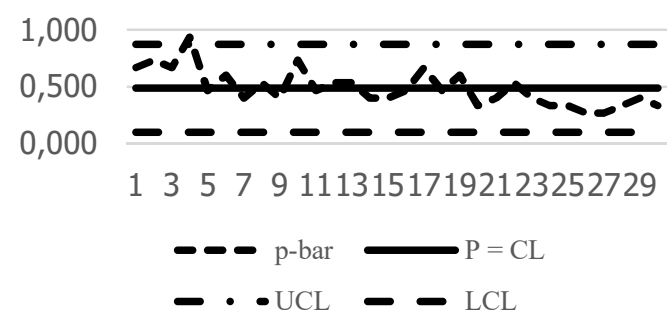

(d)

p-chart Bentuk Pinepaya

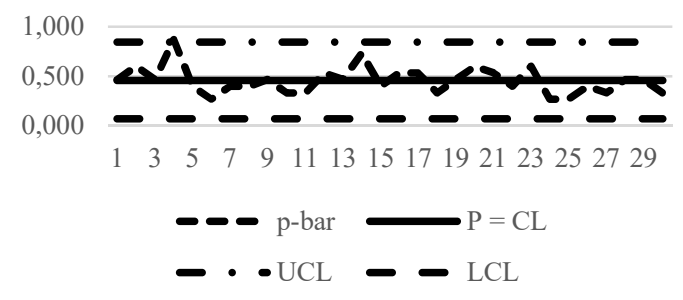

(e)

p-chart Bentuk Pisang

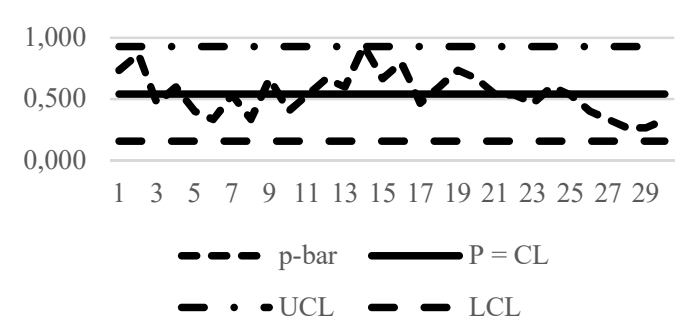

(f)

p-chart Tekstur Permukaan Mangga

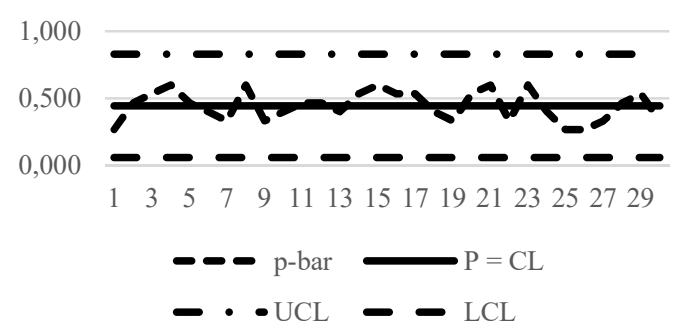

(g)

(c) 
p-chart Tekstur Permukaan Pinepaya

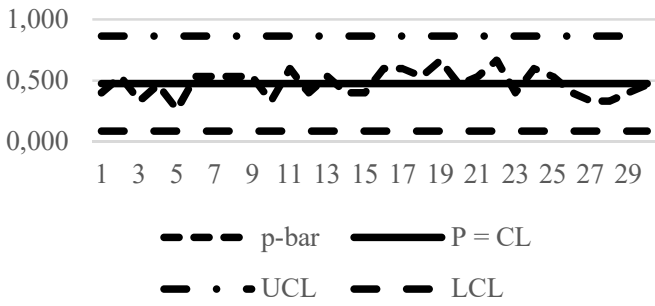

(h)

p-chart Tekstur Permukaan Pisang

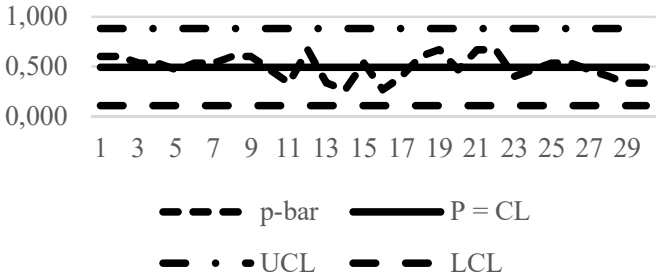

(i)

Gambar 1. Grafik p-Chart fruit strips Frutivez rasa varian mangga (a), rasa varian pinepaya (b), rasa varian pisang (c), bentuk varian mangga (d), bentuk varian pinepaya (e), bentuk varian pisang (f), tekstur varian mangga (g), tekstur varian pinepaya (h), dan tekstur varian pisang (i).

X Bar Chart Ukuran Mangga

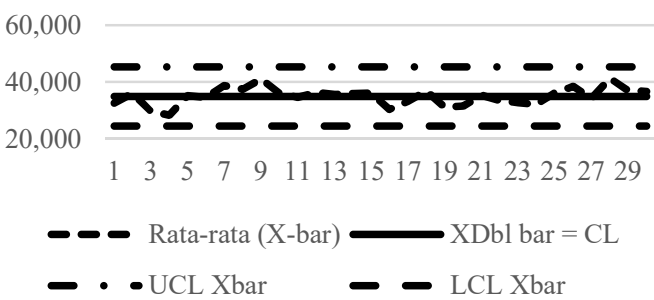

R Chart Ukuran Mangga

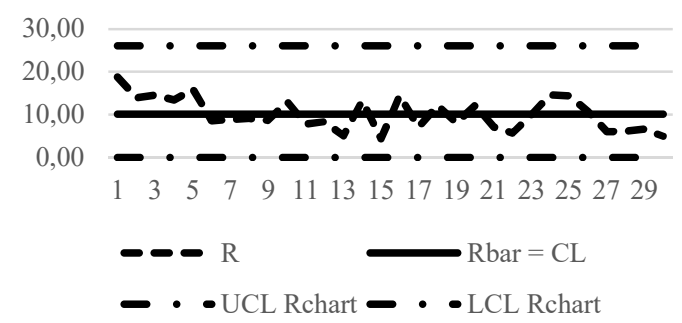

(a)
X Bar Chart Ukuran Pinepaya



R Chart Ukuran Pinepaya

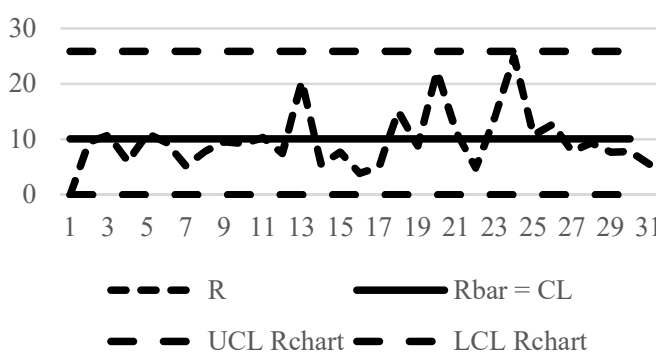

(b)

X Bar Chart Ukuran Pisang

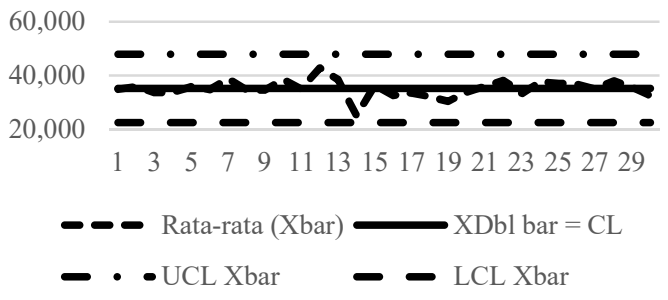

R Chart Ukuran Pisang
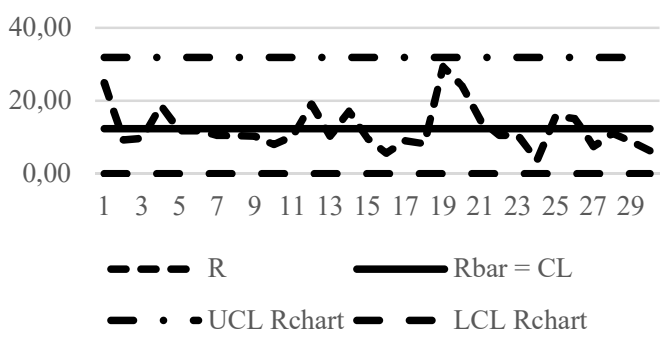

(c) 
X Bar Chart Ketebalan Mangga

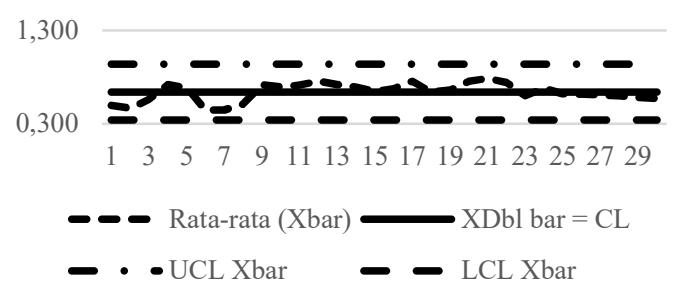

R Chart Ketebalan Mangga

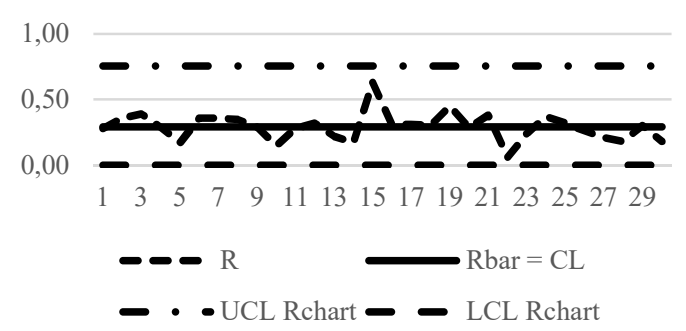

(d)



R Chart Ketebalan Pinepaya

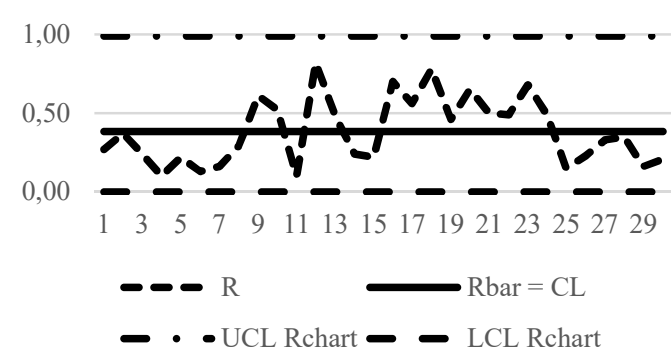

(e)
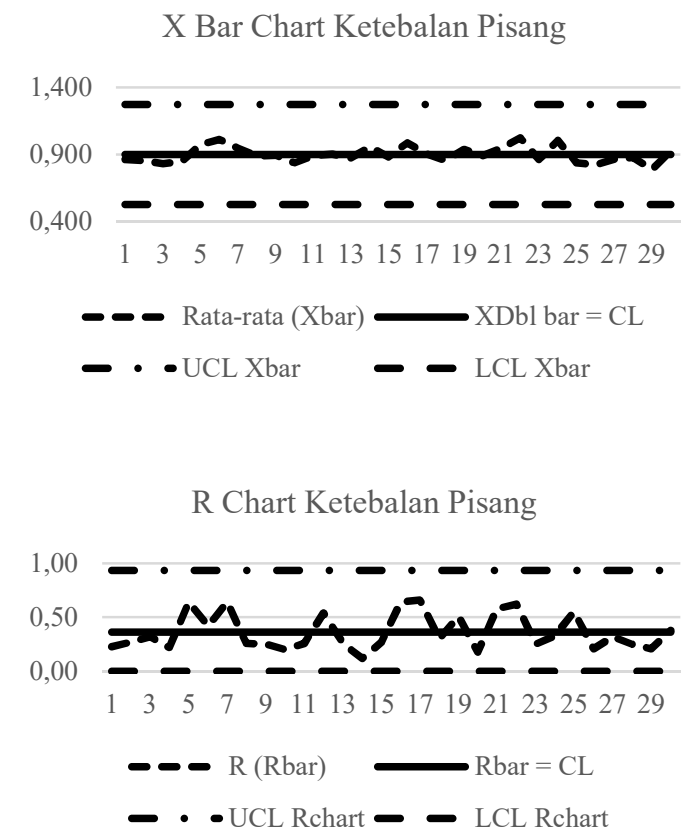

(f)

Gambar 2. Grafik X-bar - R-Chart Fruit Strips Frutivez ukuran varian mangga (a), ukuran varian pinepaya (b), ukuran varian pisang (c), ketebalan varian mangga (d), ketebalan varian pinepaya (e), dan ketebalan varian pisang (f).

Diagram sebab akibat digunakan untuk mengetahui penyebab atau masalah-masalah yang menimbulkan suatu gejala atau efek. Gejala yang ditemukan dalam penelitian ini adalah adanya penyimpangan atau kecacatan bentuk akhir produk yang diterima oleh konsumen. Analisis dilakukan dengan cara mewawancarai stakeholder yang berkaitan erat dengan produksi. Dari hasil wawancara tersebut didapatkan benar adanya bahwa bentuk akhir produk masih menjadi masalah yang kerap kali dijumpai pada produk Frutivez di setiap variannya. Hal ini disebabkan oleh 
beberapa faktor utama, yaitu tenaga kerja (manpower), metode (method), bahan baku yang digunakan (material), serta alat dan mesin yang digunakan untuk produksi (machine).

Tenaga kerja berpengaruh besar terhadap bentuk akhir produk dikarenakan proses produksi fruit strips Frutivez masih menggunakan metode manual. Kesalahan yang sering terjadi untuk kecacatan bentuk oleh tenaga kerja ini disebabkan oleh faktor internal dan eksternal. Kurir jasa pengiriman sebagai pihak eksternal yang seringkali menumpuk pesanan menjadi salah satu faktor penyebab kecacatan bentuk fruit strips (cacat patah) yang diterima oleh konsumen. Pekerja pun mengatakan bahwa pada tanggal yang terdapat data kecacatan bentuk tersebut para pekerja tidak fokus dalam memotong fruit strips sehingga hasil akhir produk banyak yang cacat. Para pekerja terkadang tidak mengenakan penutup kepala saat melakukan produksi. Hal tersebut kemungkinan merupakan salah satu faktor yang dapat mempengaruhi produk akhir fruit strips, namun untuk bentuk fruit strips tidak terlalu terpengaruhi secara langsung oleh faktor tersebut.

Selain tenaga kerja, faktor pengaruh lainnya adalah metode, dimana terdapat masalah pada cara pengiriman dan juga cara pemotongan yang masih manual. Produk dikirim oleh perusahaan menggunakan dus, bubble wrap, dan penanda pecah belah (fragile), namun ternyata hal tersebut tidak cukup untuk menjaga produk di dalamnya dari benturan dan tekanan tumpukan paket lain. Dus yang diberikan oleh perusahaan terbuat dari bahan yang tipis sehingga mudah penyok. Peralatan tray yang dimiliki oleh perusahaan pun sudah tidak rata sehingga pekerja kesulitan saat melakukan pemotongan.

Bahan baku buah yang dibeli pada waktu yang berbeda-beda berpengaruh sangat signifikan terhadap rasa akhir produk, namun demikian perbedaan waktu tersebut juga ternyata sedikit berpengaruh terhadap bentuk akhir produk. Buah yang belum terlalu matang menyebabkan bentuk pure yang dihasilkan menjadi lebih cair sehingga menjadi sulit untuk dipotong karena cenderung menjadi terlalu tipis. Maka dari itu, secara tidak langung perbedaan waktu pembelian buah menjadi salah satu faktor yang mempengaruhi bentuk akhir produk. Adapun faktor-faktor penyebab tersebut yang dirangkum dalam diagram sebab-akibat (fishbone diagram) pada Gambar 3. 


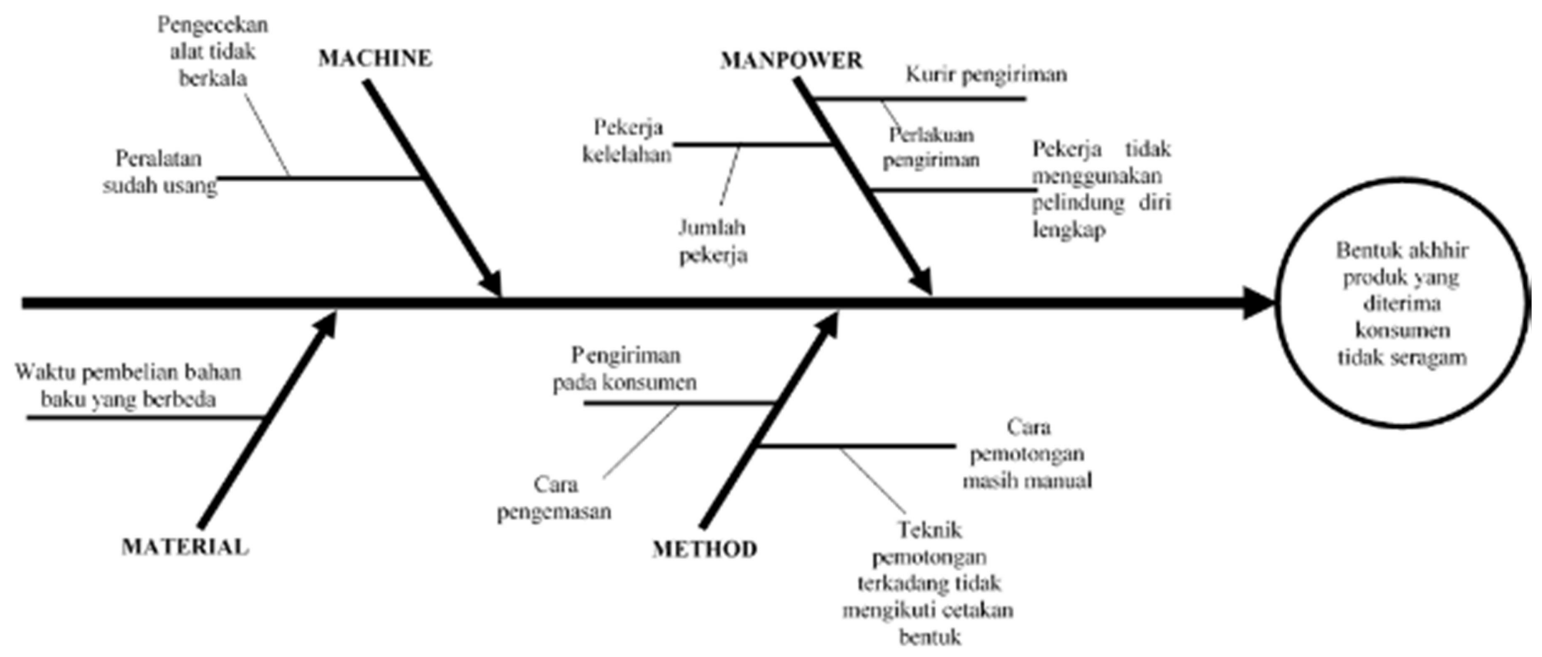

Gambar 3. Diagram Sebab-Akibat Kecacatan Bentuk Produk Frutivez

Untuk mengurangi jumlah bentuk fruit strips cacat yang diterima oleh konsumen, maka terdapat beberapa cara yang dapat dilakukan oleh perusahaan, yaitu (1) adanya penambahan opsi dus dan bubble wrap tambahan pada $e$ commerce dimana dus yang dimaksud adalah dus yang lebih tebal, (2) bonus dan rekreasi bersama (gathering) dapat diberikan oleh perusahaan guna meningkatkan solidaritas dan semangat kerja karyawan, (3) peralatan yang sudah tidak layak pakai sebaiknya diperbaiki atau dilakukan penggantian agar mempermudah proses produksi, serta (4) pembelian bahan baku sebaiknya dilakukan pada waktu yang bersamaan, namun buah perlu terlebih dahulu diolah menjadi pure dan disimpan pada lemari pendingin untuk mencegah terjadinya oksidasi.
Evaluasi dari solusi yang diberikan ini tidak dapat diamati lebih lanjut implementasinya oleh peneliti mengingat keterbatasaan waktu serta biaya yang dimiliki oleh peneliti dalam penelitian ini. Selain itu, solusi tersebut memerlukan pertimbangan lebih lanjut dari pihak perusahaaan sebelum diimplementasikan. Sehingga, untuk memvalidasi hasil penelitian ini seluruh solusi yang diberikan tersebut kemudian divalidasi terhadap pihak perusahaan untuk mengetahui persentase tingkat penerimaannya oleh pihak perusahaan. Penilaian kuesioner ini diisi oleh stakeholder yang memiliki kapasitas serta kepentingan yang sesuai, dimana pada penyebaran kuosioner ini yang dimaksud adalah internal PT. Saudagar Buah Indonesia yang terdiri atas 2 orang divisi 
produksi, 2 orang divisi marketing, dan 1 orang divisi administrasi.

Hasil dari penyebaran kuesioner tersebut didapatkan bahwa solusi (1), (2), (3), dan (4) persentase tingkat penerimaan oleh pihak perusahan secara berturut-turut adalah $87 \%, 84 \%, 81 \%$, dan $60 \%$, sehingga total persentase dari seluruh solusi yang diberikan adalah $78 \%$ atau setuju. Hasil kuosioner tersebut menunjukkan bahwa saran penulis terkait pengemasan, rekreasi karyawan, dan penggantian peralatan yang sudah usang disetujui oleh pihak perusahaan. Namun, waktu pembelian bahan baku yang diseragamkan menjadi satu minggu sekali perlu menjadi pertimbangan lebih lanjut bagi perusahaan. Hal ini disebabkan karena, perlunya penelitian dan pengujian lebih lanjut untuk formulasi dan memutuskan menerima ataupun menolak saran yang diberikan peneliti.

\section{KESIMPULAN DAN SARAN}

\section{Kesimpulan}

Fruit strips yang diminati oleh mayoritas konsumen adalah fruit strips yang memiliki rasa manis asam, berukuran antara $30-40 \mathrm{~cm}^{2}$, memiliki ketebalan $0.05 \mathrm{~mm}$, berbentuk persegi panjang, dan memiliki tekstur permukaan yang agak bertekstur. Kecacatan yang sering dijumpai pada produk fruit strips Frutivez adalah bentuk akhir produk yang patah saat diterima oleh konsumen. Kecacatan tersebut disebabkan oleh kurir yang tidak berhati-hati saat mengirimkan pesanan konsumen, cara pengemasan yang kurang aman, pekerja merasa jenuh saat melakukan produksi, serta peralatan (tray) yang sudah usang. Solusi yang diberikan adalah penambahan opsi dus dan bubble wrap tambahan pada $e$ commerce, melakukan gathering karyawan secara berkala, dan penggantian peralatan yang sudah rusak dan pemeliharaan untuk seluruh mesin dan peralatan.

\section{Saran}

Diperlukannya penelitian lanjutan guna mengevaluasi hasil solusi yang telah diimplementasi oleh perusahaan.

\section{UCAPAN TERIMA KASIH}

Penulis mengucapkan terimakasih kepada PT. Saudagar Buah Indonesia yang telah mengizinkan dilakukannya penelitian ini.

\section{DAFTAR PUSTAKA}

Amanah, D. (2010). Pengaruh Harga Dan Kualitas Produk Terhadap Kepuasan Pada Konsumen Majesty Bakery dan Cake Shop Cabang H.M. Yamin Medan. Jurnal 
Manajemen Strategi Dan Aplikasi Bisnis, 2(1), 71-87. https://doi.org/10.36407/jmsab.v3i1 .114

Elan, U., \& Kusmindah, D. H. (2016). Pengaruh Total Quality Management Terhadap Kepuasan Pelanggan pada Derpartemen BUBI (Bidang Usaha Barang Industri) PT. Varia Usaha di Gresik, 5, 178182.

Elmas, M. S. H. (2017). Pengendalian Kualitas dengan Menggunakan Metode Statistical Quality Control untuk Meminimumkan Produk Gagal pada Toko Roti Barokah Bakery, 7(Prodi Manajemen Fakultas Ekonomi UPM Probolinggo), 15-22.

Enie, A. B., \& Nami, L. (1992). Penelitian Pembuatan Makanan Ringan Asal Buah-Buahan Tropis I. Pengaruh Sulfit Dan Lama Penyimpanan Terhadap Mutu Fruit Leathers. Warta IHP, 9, 1-2.

Hamidah, D. S. (2015). Sayuran dan Buah Serta Manfaatnya Bagi Kesehatan. MAFAZA, 1-10.

Heizer, J., \& Render, B. (2011). Manajemen Operasi.

Mardiyani, D. (2018). Analisis Pengendalian Mutu Produk Piston Rod pada PT Kayaba Indonesia dengan Pendekatan Six Sigma. Skripsi Fakultas Ekonomi Dan Manajemen Institut Pertanian Bogor.

Mast, J. D. E., \& Trip, A. (2005). Gauge $\mathrm{R}$ \& $\mathrm{R}$ Studies for Destructive Measurements. Journal of Quality
Technology, 37(1), 40-49.

Montgomery, D. C. (2009). Introduction to Statistival Quality Control Sixth Edition.

Nastiti, H. (2014). Analisis Pengendalian Kualitas Produk Dengan Metode Statistical Quality Control (Studi Kasus: pada PT “ X ” Depok). Jurnal Manajemen Fakultas UPN Veteran Jakarta, 414-423.

Nissa, K. (2018). Analisis Pengendalian Mutu Proses Produksi Jamur Eringi Pada Plant Factory Ym Co, Ltd. Skripsi Fakultas Teknologi Pertanian Institut Pertanian Bogor.

Oakland, J. S. (2008). Statistical Process Control Sixth Edition.

Ramadhany, F. F., \& Supriono. (2015). Analisis Penerapan Sistem Manajemen Mutu ISO 9001 : 2015 dalam Menunjang Pemasaran (Studi pada PT Tritama Bina Karya Malang). Jurnal Fakultas Ilmu Administrasi Universitas Brawijaya, 53(1), 31-38.

Stapenhurst. (2005). Mastering Statistical Process Control.

Tarmoem, K. A. (2018). Analisis Implementasi Pengendalian Mutu Produk Mie Telor Gaga A1 di PT Jakarana Tama. Skripsi Fakultas Ekonomi Dan Manajemen Institut Pertanian Bogor.

Winarsih, S. (2017). Kebijakan dan Implementasi Manajemen Pendidikan Tinggi dalam Meningkatkan Mutu Pendidikan. Cendekia, 15(1). 